\title{
Os subterrâneos da cultura: aproximações entre Angústia e Voz de
}

\author{
prisão
}

Adriano de Almeida ${ }^{1}$

RESUMO: Este trabalho visa apontar algumas relações entre as obras Angústia, de Graciliano Ramos e Voz de prisão, de Manuel Ferreira. Entre os nexos comparativos, destaca-se a hipótese de que nas duas obras são exploradas as tensões entre discursos hegemônicos e discursos renegados ou - como pretendemos caracterizar - 'subterrâneos'. Na consideração desse embate de forças - cultural, estética, ideológico -, a função do intelectual, tal como pensada por Edward Said, será apontada como decisiva.

PALAVRAS-CHAVE: Modernismo; Graciliano Ramos; Manuel Ferreira; Papel do intelectual; Comparatismo lusófono.

ABSTRACT: This paper aims at pointing out the relationships betweenAngústia, by Graciliano Ramos and Voz de Prisão, by Manuel Ferreira. Among the comparative nexus, we have singled out the hypothesis that in both works the authors exploit the tensions between the hegemonic discourse and the discourses of the outcasts or - as we intend to characterize them 'undergrounders'. In considering this clash of forces - cultural, aesthetic, ideological -, the role played by the intellectual, as it is understood by Edward Said, will be regarded as being a decisive one.

KEY-WORDS: Modernism, Graciliano Ramos; Manuel Ferreira; the Role of the intellectual; Lusophone Comparatism.

A tradição engajada goza de grande prestígio nas letras lusófonas, apresentando inúmeros e diversificados desdobramentos ao longo do século XX, como já apontou SANTILLI (2003).

Se podemos classificar como engajada a literatura do brasileiro Graciliano Ramos, que produziu entre os anos 30 e 40, pontualmente situado,

1 Mestrando da área de Estudos Comparados de Literaturas de Língua Portuguesa - DLCV - FFLCH - USP. Título da pesquisa (provisório): Os subterrâneos da cultura - tensões entre costumes, literatura e linguagem nas narrativas Angústia, de Graciliano Ramos, e Voz de prisão, de Manuel Ferreira. Contato: adrianodealmeida1975@gmail.com 
portanto, nos anos decisivos para o estabelecimento dessa tradição no Brasil, o mesmo vale para Manuel Ferreira, autor português que produziu sua obra algumas décadas depois, entre 40 e 70, num entroncamento do neorrealismo lusitano que foi desaguar na cabo-verdianidade.

O engajamento literário se expressa, nos dois casos, na fatura literária aberta para vozes marginalizadas e no destaque para os embates discursivos em curso em seus contextos sócio-históricos.

Manuseando a linguagem de modo a ressaltar tensões, propondo um modelo literário que privilegia o questionamento, a problematização - inclusive a do próprio discurso literário - Graciliano Ramos e Manuel Ferreira, cada qual à sua maneira, abrem espaço para as vozes soterradas pelos patterns hegemônicos, permitindo a irrupção de uma "linguagem subterrânea".

\section{Um narrador desconfiado}

Tal característica - subterrânea - é costumeiramente atribuída à literatura de Graciliano, como é o caso do célebre estudo de Antonio Candido Os bichos do subterrâneo (1999). O que entendemos aqui por subterrâneo, no entanto, tem um sentido ligeiramente diferente: vemo-lo como uma voz que corre à margem dos patterns hegemônicos da cultura, uma voz inconformada e descontente com a lógica dos cultos à personalidade, uma voz que desconfia da pompa e da fala enfeitada, uma voz que é por isso mesmo silenciada e vista, por si própria, como uma "insignificância” (TORRALBO, 2009).

Desconfiança, aliás, é a palavra-chave para entender a relação de Luís da Silva com a linguagem, com a cultura, com o meio em que vive. Intelectual socialmente inexpressivo, ele constrói um discurso corrosivo acerca da cultura letrada, representada sobretudo por Julião Tavares, medalhão social que figura na galeria dos intelectuais bajuladores do poder, perfeitamente enquadrados na retórica beletrista tão achincalhados pelos modernistas; É famosa esta 
declaração de Graciliano Ramos: “A palavra não foi feita para enfeitar, brilhar como ouro falso. A palavra foi feita para dizer." 2

Além de valer como caracterização de todo o projeto literário do autor o qual e não cabe aqui explorar -, tal declaração está intimamente ligada à desconfiança que Luís da Silva tem em relação à cultura oficial. E se é verdade que essa desconfiança dirige-se também para outros aspectos e atores sociais (talvez ela valha mesmo para o próprio estar-no-mundo de Luís da Silva), é possível dizer que ela se mostra mais contundente quando se dirige aos representantes da cultura oficial: o que talvez seja uma das explicações para o assassínio de Julião Tavares - e não de algum outro personagem, como, por exemplo, Moisés, o judeu comunista, de cujo discurso Luís da Silva - é importante lembrar - também desconfia, embora tenha esse homem como seu interlocutor.

Julião Tavares é uma existência exibida, extrovertida, loquaz: “Gordo, bem vestido, perfumado e falador" (RAMOS, 1975, p. 46). Trata-se de um bacharel, um homem de prestígio.

Seu destaque social é imediatamente interpretado por Luís da Silva como o brilho de um "ouro falso": na primeira menção ao rival, o narrador já o faz como processo de desmascaramento, apontando desde logo para a impostura, o caráter ludibriador desse brilho:

Os jornais andaram a elogiá-lo, mas disseram mentira. Julião Tavares não tinha nenhuma das qualidades que lhe atribuíram. Era um sujeito gordo, vermelho, risonho, patriota, falador e escrevedor. No relógio oficial, nos cafés e noutros lugares frequentados cumprimentava-me de longe, fingindo superioridade

\footnotetext{
2 Conforme o site Observatório da Imprensa, essas palavras foram ditas por Graciliano Ramos em entrevista concedida no ano de 1948: http://observatoriodaimprensa.com.br/news/showNews/al050320034.htm Acesso em 26 maio 2012.
} 
Linguagem arrevesada, muitos adjetivos, pensamento nenhum. (RAMOS, 1975, p. 26)

A certa altura, numa frase conclusiva, Luís da Silva comenta: “Tudo nele era postiço" (p. 48).

A fala de Julião é descrita por Luís como limpa, aprumada, lisa - "As palavras corriam-lhe facilmente (...)" (p. 75) -; como "uma voz líquida e oleosa que escorria sem parar" (p. 72).

Em contraposição, Luís da Silva vive como um ser confuso e complicado:

Apronto-me, calço as meias pelo avesso e saio correndo. Paro sobressaltado, tenho a impressão de que me faltam peças do vestuário. Assaltam-me dúvidas idiotas. Estarei à porta de casa ou já terei chegado à repartição? (p. 72)

Sua figura social, ao contrário da de Julião, é inexpressiva, não sugere brilho, mas opacidade e sombra:

Os olhos estão quase invisíveis por baixo da aba do chapéu, e uma folha da porta oculta-me o corpo. Uma criaturinha insignificante, um percevejo social, acanhado, encolhido (...) (p. 20)

Luís conhece seu lugar de insignificância e condena o seu papel como intelectual medíocre, descrevendo suas ocupações como “cacetes" (p. 44), vendo-as inclusive como um meio de "defender sujeitos que deviam ser atacados" (p. 44). É portanto um ator social que desconfia de seu campo (BOURDIEU, 1989) e que o desmistifica em seu relato:

Alguns rapazes vêm consultar-me: 
- Fulano é bom escritor, Luís?

Quando não conheço Fulano, respondo sempre:

- É uma besta.

$(\ldots)$

As frases iam pingando no papel, umas traziam as outras, e no fim lá estava aquela prosa medida, certinha, que enjoava. (RAMOS, 1975, p. 44)

Luís da Silva emprega essa prosa que o "enjoava" apenas por obrigação “esse osso que vou roendo com ódio" (p. 24) -, mas é bem diferente o seu modo de se expressar quando, fora da situação de empregado, pode falar livremente:

A minha linguagem é baixa, acanalhada. Às vezes sapeco palavrões obscenos. Não os adoto escrevendo por falta de hábito e porque os jornais não os publicariam, mas é a minha maneira ordinária de falar quando não estou na presença dos chefes. (p. 47)

É assim, com essa linguagem "baixa", que conversa, espontaneamente, com seus conhecidos Seu Ivo e Moisés.

Essa espontaneidade linguística logo se acanha à chegada de Julião Tavares, que traz o tom oficial e bajulador dos patterns hegemônicos, sujeito acomodado em seu habitus (BOURDIEU, 1989).

Os trechos que seguem mostram bem a diferença entre as posturas:

Diante dele [Julião Tavares] eu me sentia estúpido, esfregava as mãos com esta covardia que a vida áspera me deu e não encontrava uma palavra para dizer.

As nossas conversas são naturais, não temos papas na língua. Abro um livro, fico alguns minutos fazendo cacoetes, de repente dou um grito: 
- Que sujeito burro! Puta que o pariu! Isto é um cavalo.

Moisés toma o volume, lê uma página com atenção, fungando:

- Tem ideias boas, tem ideias.

- Que ideia! Isso é um sendeiro, não sabe escrever.

Julião Tavares veio tornar impossíveis expansões assim. Dizia, referindo-se a um poeta morto:

- Era um grande espírito, um nobre espírito. Quanta emoção! Além disso conhecimento perfeito da língua. Artista privilegiado. (RAMOS, 1975, p. 47)

O discurso de Julião é marcadamente vinculado a uma intelectualidade bajuladora, presa a um ideário beletristra, passadista, com declarações romântico parnasianas - como fica patente nos elogios que faz ao tal "poeta morto": "um nobre espírito. Quanta emoção! Além disso conhecimento perfeito da língua". Palavras que serviriam perfeitamente como alvo de zombaria e sarcasmo aos modernistas de 20, em seu combate ao "o lirismo namorador / político" (BANDEIRA, 1997, p. 26).

Angústia, como fatura romanesca, é, ao contrário disso, um livro descontínuo, insólito, delirante, "verrumante", como disse Schnaiderman em relação à prosa de Dostoiévski (2000, p. 7) - uma voz de renúncia ao pattern discursivo aceitável, fácil, "líquido" ou "oleoso"; e, como observou Bulhões, um texto "em confronto com 'o texto do outro'” (1999, p. 18).

\section{Polifonia e tensão}

Em Voz de prisão, de Manuel Ferreira, encontramos uma narrativa também marcada pelo confronto entre registros, a qual tensiona e questiona a relação do pattern cultural hegemônico com o discurso marginalizado: respectivamente, a cultura europeia e a cultura cabo-verdiana.

Diferentemente de Angústia, que tem um narrador-personagem centralizador da enunciação, Voz de prisão põe a falar várias vozes, 
entrecruzando-as vertiginosamente, sem transições claras, no mais das vezes deixando as demarcações por conta do próprio leitor. O que marca a narrativa é, como afirma Abdala Jr., “(...) não uma voz monológica, com prescrições autoritárias de poder, mas um poder que se afirma no diálogo, com sobreposições dialéticas de várias perspectivas." (2007 b, p 131)

Essa particularidade composicional de $V o z$ de prisão resulta numa rede contrastante de registros, em que a língua portuguesa está ao lado da caboverdiana, ora em sentido colaborativo, ora em sentido de embate.

A marca de hibridismo aparece na narrativa também por meio da mistura de gêneros discursivos: a enunciação é por vezes atravessada por citações não-literárias, as quais levam a narrativa para um plano mais reflexivo e que inscreve o "papiar" das personagens no chão histórico da tensão entre oprimidos e opressores. Entremeada à enunciação, está a voz do intelectual, que se dirige aos personagens e ao mesmo tempo ao leitor, problematizando o que presencia, escuta e vê.

Nha Joja, cabo-verdiana emigrada para Lisboa, identifica-se com a cultura hegemônica - europeia - e busca apagar as marcas de sua africanidade, incluindo a língua crioula. Ela pretende educar Vítor, seu filho adotivo, segundo os costumes europeus:

Vítor quer ser eletrónico ou lá que é. Feiinho, coitado, mas uma cabeça, com esperteza no corpo. Fala um português correcto. Só visto. Nha Joja, deve falar também crioulo mais o Vítor para ele não perder o hábito - interrompi. É a língua dele. Ah, pois, falamos crioulo aqui na casa. Falo crioulo com o Vítor. Ele gosta. É o que eu digo a Vítor. Hora que gente papiá crioulo é crioulo, hora que a gente papiá português é português. Obrigo-o a pronunciar direito, a não enrolar as sílabas, a não abrir os ee. Quando desembarcou ele vinha brabo. Às vezes ele dizia, mamãe (...), fulano me disse, eu emendo-o logo. Vítor, não é ele me disse, é ele disse-me. Isso é falar brasileiro. Um 
português bem falado, uma pronúncia puxada dá importância à pessoa, dá distinção, não é deveras? (FERREIRA, 1978, p. 13)

Como se pode ver, os comentários de Joja têm interferência do narrador-personagem anônimo, o intelectual que problematiza o discurso da mulher e a obriga, com isso, a explicar-se e, por fim, acabar deixando explícita sua sujeição à cultura dominante.

Assinalemos o fato de que a fala crioula, para nha Joja, é aceitável dentro dos limites domésticos, em situação familiar, ou seja, fora da cena pública, onde é estigmatizada como forma desviante e inculta. Essa intimidação linguística - que empurra o crioulo e o que ele representa para o subterrâneo da comunicação - aproxima-se bastante daquela outra, detectada em Luís da Silva quando diante de Julião Tavares, um representante dos patterns oficiais.

E vão aparecendo, no desenrolar do enredo e o entrecruzar de vozes, atores sociais contrários ao assimilacionismo.

A certa altura do livro, por exemplo, encontramos este comentário do narrador:

Estou pensando no Vítor Manuel e na nha Joja, nessa máquina de fazer esquecer o tempo, nesse jeito de adoçar a vida, a dizer-nos lá na sua casa que tomara mocinho preto, um mocinho esperto comâ intentação. Dondê ele? Chegará hoje mais nha Joja? Meus olhos percorrendo as lombadas de alguns livros, tomando sentido nos autores que vêm desafiando esse mundo da absurdidade e da bruteza. Do racismo. Dessa vida de dor do racismo. Da desabusada grita dos escritores e poetas africanos, furando como formiga. (...) O espírito alevantado de Sartre. Frantz Fanon. Adê, Fanon um moço violento comâ intentação. Aimé Césaire e suas armas miraculosas do negro antilhano afrontado. (FERREIRA, 1978, p. 40) 
"Percorrendo as lombadas" dos livros, o narrador vai nos mostrando os caminhos contrários à assimilação cultural, sugerindo, a partir de um repertório teórico-crítico, outra percepção da realidade apresentada por nha Joja.

A figura de Vítor Manuel, embora intermitente, é central na narrativa. Nha Joja, a certa altura, comenta a seu respeito:

Vocês sabem, é um mocinho muito esperto mas agorinha ele anda com umas ideias estrambólicas. Fecha-se no quarto, a ler, a escrever, metido na poesia, nunca pára de escrever. (p. 129)

O engajamento na causa da afirmação étnico-cultural passa pela leitura, pelo estudo, pela compreensão teórica dos fenômenos, que, então desnaturalizados, podem mover os atores sociais (e o destino da narrativa) para uma perspectiva crítica. A visão alienada, conformista de nha Joja vai sendo, dessa e de outras maneiras, minada ao longo do texto.

Outros estudantes, companheiros de Vítor, cumprem esse papel questionador da lógica assimilacionista. É o caso de Zilda, cujas ações de afirmação étnico-cultural geram embate significativo no texto:

Amô, Zilda, dias-há estavas tão bonitinha com teu cabelo desfrizado, agora vens assim com ele por arranjar. Não foi só Joja a mostrar sua estranheza. Zilda tinha chamado a atenção doutras pessoas que a conheciam. Qual, este é o meu cabelo, nha Joja. Pamóde quê não hei-de usá-lo assim mesmo? Riu-se, uns dentes bonitos. Menina, mas tu duma vez desfrizálo. Duma vez desfrizavá-os, agora não. Nha Joja, esconder que é nosso por quê? Eles são de uma maneira, nós somos de nossa maneira. Cabo-verdiano tem de ser cabo-verdiano na tudo, não é deveras? Nunca Joja tinha ouvido uma coisa assim. (p. 123) 
O trecho é rico por apresentar a tensão entre duas posturas: a da jovem que vê a afirmação de seus traços fenotípicos como fundamental à superação da opressão e do princípio hierárquico entre as raças e culturas, ou seja, um ator social plenamente convencido da necessidade de expressar seu modo de ser, como contraponto e como equivalente étnico-cultural ("eles são de uma maneira, nós somos de nossa maneira"): não como inferior. De outro lado do embate, temos nha Joja, que recrimina a moça, como se sua postura fosse de "descuido" estético - subordinando, portanto, a beleza feminina aos patterns fenotípicos das mulheres de cabelo liso: à beleza das mulheres brancas/europeias.

Ressalte-se ainda a voz do narrador, que chama a atenção do leitor para o evento, destacando o choque vivido por nha Joja.

A cultura renegada vai aos poucos minando os espaços da narrativa, irrompendo de variadas formas, ganhando terreno, mesmo no pensamento de nha Joja, que já passa a titubear:

Nha Joja espiava-os com olhos de intentação. Seu cabelo era liso, mas se fosse grosso, encrespado, desfrizá-lo-ia, pois então. Se achava mais bonito, que tem uma coisa a ver com outra? Tinha, insistia, aqueles moços. "As raparigas negras aprenderam a usar o cabelo encarapinhado. Os negros olharam com novos olhos a sua cultura" (América em Fogo, James Hepburn) (p. 124)

Joja não percebe ou finge não perceber o poder simbólico que está em jogo. "Aqueles moços" engajados na luta contra a supremacia racial, em busca de afirmação do povo negro, apontam o caráter revolucionário da atitude: não se trata apenas de opção, de gosto pela aparência ou idiossincrasia. E o que vem em resposta - a citação de James Hepburn - já não sabemos se são palavras ditas por eles ou um texto "colado" pelo próprio narrador (ou já 
devemos dizer escritor?). Ao final da narrativa, vale lembrar, Joja acaba por ver a si própria como um ator que contribui para a luta contra a submissão de seu povo.

O trecho citado é mais um exemplo da opção de Manuel Ferreira pela orquestração plurívoca, polifônica, em que vários agentes discursivos interferem na tecedura da trama, dando dinamismo (até vertiginoso) à narração e inscrevendo-a num processo de debate histórico, coletivo - um debate ou um embate em processo.

Os subterrâneos da cultura vão, gradativamente, ganhando novas conotações na narrativa, e, com sua força consciente e insistente, abrem espaço, produzindo uma nova percepção da realidade.

\section{Edward Said e o papel do intelectual}

A escrita engajada é feita a contrapelo da ideologia dominante. Por ser literatura, ressignifica os códigos do real, apontando caminhos ainda não vistos; por ser engajada, tem como escolha os pontos de conflito da realidade, investindo suas forças na denúncia da opressão, abrindo espaço para os textos indesejados pelo discurso hegemônico, empenhando-se em representar os subterrâneos da cultura, aos quais dá estatuto estético.

Essa função do intelectual foi abordada de modo expressivo por Edward Said no texto Representações do intelectual (2005), no qual o autor diferencia a atividade intelectual das outras profissões, afastando a ideia de que ela seja apenas uma especialização ou uma competência técnica favorável ao bom funcionamento do sistema. O intelectual, para Said, ao contrário, é alguém que deve estar empenhado em provocar a opinião pública, posicionando-se criticamente, exatamente por possuir uma capacidade especial de representação: seja como artista, educador ou comunicador.

Não é possível, para Said, pensar em atividade intelectual como algo desvinculado de um chão histórico e social: 
A política está em toda parte; não pode haver escape para os reinos da arte e do pensamento puros nem, nessa mesma linha, para o reino da objetividade desinteressada ou da teoria transcendental. Os intelectuais pertencem ao seu tempo. (2005, p. 34)

A função principal do intelectual, para o autor, é usar seu conhecimento para dar voz àqueles que têm menos chances de se expressar:

Há uma discrepância inerente entre os poderosos de grandes organizações (de governos a corporações) e a relativa fraqueza não só de indivíduos, mas de seres humanos considerados subalternos, minorias, pequenos povos e Estados, culturas e etnias menores ou subjugadas. Não tenho nenhuma dúvida de que o intelectual deve alinhar-se aos fracos e aos que não têm representação. (p. 35)

Mas a posição crítica que Said cobra do intelectual não é a do "pacificador" nem a do "criador de consensos", e sim a de

(...) alguém que empenha todo o seu ser no senso crítico, na recusa em aceitar fórmulas fáceis ou clichês prontos, ou confirmações afáveis, sempre tão conciliadoras sobre o que os poderosos ou convencionais têm a dizer e sobre o que fazem. (p.36)

Pensando o intelectual como alguém que deve estar "em estado de alerta constante" (p. 36), Said destaca sua responsabilidade quanto ao manejo da língua. Valendo-se de palavras de George Orwell, lembra que:

Clichês, metáforas gastas, textos preguiçosos, diz Orwell, são indícios da "decadência da língua". O resultado é 
que a mente é anestesiada e permanece inativa, enquanto a língua, que produz um efeito de música de fundo num supermercado, faz submergir a consciência, seduzindo-a para uma aceitação passiva de ideias e sentimentos inquestionáveis. (SAID, 2005, p. 39)

Ou seja, o intelectual deve ter consciência de que a língua não é uma estrutura monolítica ou estática e que, quando a manuseia, tem opções que podem e devem tirá-la da previsibilidade e da "naturalidade" falaciosa.

Essas considerações acerca do papel do intelectual são altamente produtivas para se pensar os textos narrativos em questão.

Angústia é um exemplo claro desse "estado de alerta constante" (SAID, 2005, p. 36): a consciência problematizadora e desconfiada de Luís da Silva que chega ao patológico -, abrange a condição de intelectual dele mesmo, toca Julião Tavares, que é a figura emblemática do intelectual conservador e atinge também o discurso da esquerda brasileira de seu tempo. São problematizações perceptíveis não apenas no nível da efabulação, mas na estruturação do romance (prosa vertiginosa, não-linear, "verrumante", estrutura em abismo).

Voz de prisão, com seu entrecruzar de vozes assentado no "papiar", dá força e forma estética para atores e registros sócio-culturais de menor prestígio, abordando os "subterrâneos da cultura". A presença do intelectual, na enunciação do texto, como interlocutor disposto a desafiar os pressupostos da ideologia dominante, com suas provocações e convocações.

As convicções de Said ajudam-nos a confirmar a relevância de obras como a de Graciliano Ramos e Manuel Ferreira e de toda a linhagem engajada da tradição lusófona.

\section{Referências bibliográficas}

ABDALA JR., Benjamin. Literatura, história e política - literaturas de língua portuguesa no século XX. São Paulo, Ateliê Editorial, 2007. 
Voz de prisão, voz de libertação. In: Revista Colóquio/Letras,número73. São Paulo/Lisboa, 1983. p. 29-34.

BANDEIRA, Manuel. Vou-me embora pra Pasárgada e outros poemas. Rio de Janeiro,Ediouro, 1997.

BOURDIEU, Pierre. "A gênese dos conceitos de habitus e de campo". In: O poder simbólico. Lisboa, Difel, 1989.

BULHÕES, Marcelo Magalhães. Literatura em campo minado - a metalinguagem em Graciliano Ramos e a tradição literária brasileira. São Paulo, Anablume, 1999.

CANDIDO, Antonio. Ficção e confissão - ensaios sobre Graciliano Ramos. Rio de Janeiro, Ed. 34, 1999.

CARVALHO, Lúcia Helena. A ponta do novelo - uma interpretação de Angústia, de Graciliano Ramos. São Paulo, Ática, 1983.

FERREIRA, Manuel. Voz de prisão. Lisboa, África Editora, 1978.

GIMENEZ, Erwin Torralbo. 'Graciliano Ramos, uma poética da insignificância'. In: Estudos Avançados - volume 23, número 67, São Paulo, Instituto de Estudos Avançados da USP, 2009. p. 231-250.

RAMOS, Graciliano. Angústia. Rio de Janeiro, São Paulo, Record/Martins, 1975.

SAID, Edward. Representações do intelectual. São Paulo, Companhia das Letras, 2005.

SANTILLI, Maria Aparecida. Paralelas e tangentes entre literaturas de lingua portuguesa. São Paulo, Arte e Ciência, 2003.

SCHNAIDERMAN, Boris. Prefácio do tradutor. In: DOSTOIÉVSKI, Fiódor. Memórias do subsolo. São Paulo, Editora 34, 2000. p. 7.

TORRALBO. 'Graciliano Ramos, uma poética da insignificância'. In: Revista Estudos Avançados, número 67. São Paulo, 2009. p 231-250. 